\title{
Impact of Intervention Practices on Malaria Treatment Outcomes Among Patients in Bushenyi District, Uganda
}

Josephat Nyabayo Maniga

Kampala International University - Western Campus

David Kalenzi Atuhaire

Kampala International University - Western Campus

Claire Mack Mugasa ( $\nabla$ claire1mack@covab.mak.ac.ug )

Makerere University College of Veterinary Medicine Animal Resources and Biosecurity

https://orcid.org/0000-0002-7208-7120

\section{Research}

Keywords: Treatment, Interventions, Malaria, Bushenyi

Posted Date: February 17th, 2021

DOl: https://doi.org/10.21203/rs.3.rs-204112/v1

License: (a) (i) This work is licensed under a Creative Commons Attribution 4.0 International License. Read Full License 


\section{Abstract}

Background

Malaria remains a major vector borne disease causing both mortalities and morbidities in the world. Uganda as a country has currently scaled out major campaigns to reduce and eliminate the disease using different interventions. However, there is no clear data on the impact of such interventions on malaria treatment outcomes. Therefore, this study was aimed at assessing the impact of malaria intervention practices on Artemether- Lumefantrine (AL) treatment outcomes among the residents of Bushenyi district, Uganda, a high intensity malaria transmission area.

Methods

This was a descriptive cross-sectional study carried out among 184 study participants for a period of one year (August 2017 to August 2018) in four selected health centers in Bushenyi district, Uganda. The investigative methods used included a researcher administered questionnaire, laboratory and clinical evaluations of participants. Data analysis was done by using statistical package for social sciences (SPSS version 10 windows) for descriptive statistics.

Results

Statistically significant factors for treatment outcome at $\mathrm{p} \leq 0.05$ were; practicing indoor residual spraying (IRS) at home $(P=0.001 ; \mathrm{Cl})$, source of prescription $(P=0.018 ; \mathrm{Cl})$, finishing dosage $(P=0.006 ; \mathrm{Cl})$, frequency of malaria infection $(P=0.028 ; \mathrm{Cl})$, Frequency of antimalaria usage $(P=0.042 ; \mathrm{Cl})$ and sleeping under insecticide treated nets $(\mathrm{ITNs})(P=0.039 ; \mathrm{Cl})$ respectively.

Conclusions

IRS and ITNs were found to be the major intervention practice of malaria reduction after treatment with ACTs.

\section{Background}

Malaria infection remains the most prevalent vector borne disease [1] and is transmitted by the female anopheles mosquito. The major species involved in transmission in the sub Saharan Africa include Anopheles gambiae (complex), Anopheles funestus and Anopheles maculipalpis [2]. Malaria occurs in over 90 countries worldwide with the majority of cases reported in Sub Saharan Africa. Each year an estimated 300 to 500 million clinical cases of malaria occur, making it one of the most common infectious diseases worldwide [3]. Over $90 \%$ of the Ugandan populations are at risk of the infection [4]. Malaria management programs have positively reduced malaria. It has been recently documented that since 2000, 37 countries in continents other than Africa have experienced at least a 75\% reduction in newly reported malaria cases [5]. Malarial intervention methods used to reduce malaria burden include: appropriate diagnostic testing, Insecticide treated nets (ITNs), insecticide residual spray (IRS), intermittent preventive therapy (IPT) in pregnant women and infants. In 2015, World Health Organization (WHO) recommended universal coverage 
for ITNs use by all persons in all households [6]. WHO also recommends the provision for adequate laboratory testing of all suspected malaria episode. In relation to the Roll Back Malaria Initiative developed from the United National Millennium Development Goals, extensive interventions has greatly reduced malaria; by $40 \%$ in sub-Saharan Africa, However, these gains are being compromised by the evolution and spread of Plasmodium [7]. According to the Uganda Demographic Health Survey in 2018/2019, 83\% of the total population was in possession of at least one ITNs per a house hold. However, it was noted that ownership was directly proportional to the wealth index. West Nile region had the highest possession of ITNs at $92 \%$, with Karamoja region having the lowest ownership of the ITNs at $58 \%$. Ankole region where the current study area is located had the ownership of ITNs at $86 \%$. [8]

In 2012, 88 countries in Africa were implementing IRS, and the number of people at risk protected by IRS increased from $5 \%$ in 2005 to $11 \%$ in 2010 . However, it has been shown that resistance to insecticides has emerged as a problem in Africa [9]. Intermittent Preventive Treatment in Pregnancy (IPTp) is one of the methods that have been employed to control malaria in pregnant women; however, its coverage is still limited. Pregnant women presents one of the major risk group for malaria infection and malaria in pregnant women may not always manifest as febrile illness, but it leads to severe anemia, low birth weight and other fetal abnormalities [10]. It was documented in 2019 that in 2018 worldwide, only $60 \%$ of pregnant women received one dose of IPTp, while $49 \%$ received two doses and $31 \%$ received three doses [11]; generally, coverage of the required three doses of IPTp was inadequate. For instance, a previous retrospective study conducted in 2019 in Uganda revealed that uptake of three or more doses of IPTp was 18\%. This was a follow up analysis of data from the Uganda demographic and Health survey, 2016 [12]. In contrast, a recent study conducted in Uganda, reported that $41 \%$ of mothers who had given birth two years before the survey received three or more doses of IPTp during their immediate previous pregnancy [13].Therefore, malaria intervention methods have been impressive in the world though it remains unclear what overall reduction in transmission is obtainable by using currently available interventions. Thus, the current study was aimed at assessing the impact of malaria intervention practices on malaria treatment outcomes after treatment with the currently recommended drugs of ACTs in Bushenyi district, Uganda, a high intensity malaria transmission area.

\section{Methods}

\section{Study area}

This study was carried out in Bushenyi District, Uganda (Figure 1). The district has eleven (11) Sub-counties; 76 parishes and 529 villages. The district is located approximately 380 kilometers from the capital city, Kampala. It lies on latitude: $0^{\circ} 29^{\prime} 27.6^{\prime \prime}\left(0.491^{\circ}\right)$ South, longitude: $30^{\circ} 10^{\prime} 58.8^{\prime \prime}\left(30.183^{\circ}\right)$ East. The district has a total land of 3,949 square kilometers and it lies between 910 and 2,500 meters above the sea level. It is hilly with forest and swampy vegetation and is characterized by seasonal water bodies, net-works of streams, stagnant pools, over filled blocked gutters and drainages. The region experiences three wet seasons (April-May, August-September, and November-December) and one dry season (January and February); the temperatures are about $25^{\circ} \mathrm{C}-37^{\circ} \mathrm{C}$ no wonder the major economic activity of this community is agriculture. The communities reside mainly in semi-permanent and mud-thatched houses. It has over 
grown bushes and fields of bananas around residential homes which favors the survival and multiplication of mosquitoes. The land under cultivation consists of 2,215 square kilometers and wetlands covers 183 square kilometers.

This study was conducted at the four selected health centers, namely; Kampala International University teaching hospital, Ishaka Adventist hospital, Kyamuhunga health centre and Kyeizooba health Centre. The study area has an entomological inoculation rate (EIR) of 100 per annum [14] and Anopheles gambiae and Anopheles funestus are the main malaria vectors in the region. The control methods which have been scaled up by the government in this region to prevent malaria infection include proper case management with antimalaria drugs such as ACTs, intermittent prophylaxis during pregnancy (IPTp), use of mosquito nets and indoor residual spraying (IRS) [15].

\section{Study Design and study population}

This was a descriptive cross-sectional study carried out to assess the influence of malaria intervention practices on in-vivo Artemether- Lumefantrine (AL) treatment outcomes in Bushenyi district, Uganda. The investigative methods included questionnaire, laboratory and clinical evaluations. The study participants were recruited from the health facility regardless of the age specifications.

\section{Inclusion criteria}

All participants were out-patients who were presenting with signs of uncomplicated malaria to the clinician in-charge; those who had resided in Bushenyi district for at least the last six months prior to the commencement of the study, those who confirmed that they were able to comply with the stipulated followup visits, and those without severe malnutrition as per the 2015 WHO guidelines.

\section{Exclusion criteria}

Those who declined to consent to the study, nomadic patients, intolerant to oral treatment according to modified WHO 2010 criteria, hypersensitivity or allergy to ACTs, Febrile conditions due to other malaria, and those under medications which may have interfered with pharmacokinetics of anti-malarial drugs and those with severe malaria as per the WHO guidelines were excluded.

\section{Study setting}

All adult patients signed the informed consent form and parents or guardians signed the informed consent on behalf of the patients below 18 years. Out of the 283 participants recruited to this study, 194 completed the follow up schedules while 89 were withdrawn from the study because they did not adhere to the follow up visits in the first three days.

\section{Questionnaires}

The study was conducted by using pre-tested administered questionnaires which were used to determine the demographic patterns and effects of malaria intervention programs used by the participants to prevent malaria infection. The questionnaires were developed from the demographic health survey (DHS). This was 
adapted to reflect the population and health issues relevant to malaria infection in Uganda [17]. The questionnaire was pretested to verify for clarity and administerbility. Consequently, questionnaires were translated to the two most common local languages of Luganda and Runyankole. Information on the following independent variables was collected; socio-demographic parameters (age, sex, number of members in each household, educational level of patient or household head, protective facilities from mosquito bite, symptoms of malaria experienced, frequency of taking anti- malarial drugs, misuse of ant malarial agents, prescription of drugs, hospital visit for fever management, pattern of febrile illness, dwelling unit long-lasting insecticidal nets (LLIN) use, indoor residual spraying (IRS) in the household and intermittent preventive treatment of pregnant women (IPTp) intake were determined [18]. Every participant was allocated a unique recognition code at the time of the questionnaire administration. The names of respondents and households were kept as total confidential information and were not to be used in the presentation of results or available to anybody.

\section{Determination of malaria treatment outcomes}

The Plasmodium falciparum positive participants were treated with Artemether-Lumefantrine (AL) drug and monitored at day $0,1,23,7,14$ and day 28 . The efficacy of the Artemether-Lumefantrine (AL) treatment was assessed as previously described [19] by evaluating clinical and parasitological outcomes as per the WHO in-vivo clinical and parasitological classification criteria for areas of intense malaria transmission [20] which classifies the response as adequate clinical and parasitological response (ACPR) if there is no treatment failure, late parasitological failure (LPF) if $P$. falciparum parasitemia occurs between 4 and 28 days without fever, late clinical failure (LCF) if $P$. falciparum parasitemia occurs between 4 and 28 days with fever and finally as early treatment failure (ETF) if there is development of severe symptoms, or insufficient parasitological response by day three.

\section{Data analysis}

Data was entered in excel spread sheet 2007, by considering different parameters against the study participants. Data retrieved was analyzed using statistical package for social sciences (SPSS version 10 windows). Descriptive statistics was done using tables showing frequencies and percentage distributions. Factors that were statistically significant $(p \leq 0.05)$ at bivariate analysis were included in the multivariate analysis. The model was checked for best fit of data and then used to compute adjusted odds ratios of factors that were associated with malaria treatment outcomes. Statistical significance was considered at $95 \%$ level of confidence. Interaction and confounding factors were assessed, and values of $p \leq 0.05$ were regarded as statistically significant relationships.

\section{Results}

\section{Baseline characteristics of the participants}

The study recruited 283 respondents, 194 (68.6\%) participants completed the follow up schedules while 89 (31.4\%) were withdrawn from the study due to violation of the study protocol. The participants were grouped in relation to their social demographic patterns such as age, gender and weight as presented in Table 1. By 
considering the age, participants with 0-5 years represented the least number of $3(1.5 \%)$ in relation to those having 18 years and above who were the majority with 115 (59.3\%). The median age of the study participants was 22.5 years with the median range 1-108 years and interquartile range (IQR) $=14-36$ years. In relation to the weight of the participants majority of the study participants were weighing more than $31 \mathrm{~kg}$ with $167(86.1 \%)$ participants. The median weight was $52.5 \mathrm{~kg}$, median range was 8.5-82 and interquartile range (IQR) was $38-62 \mathrm{Kg}$ respectively. In relation to the occupation of the participants, students/ pupils represented the highest number with 84 (43.3\%).

\section{Malaria treatment practices associated with treatment outcomes}

The current study found that the majority of participants used ACTs with a rate of 164 (84.5\%). After treatment with ACTs, the study recorded an Adequate Clinical and Parasitological Response (ACPR) of 50 (30.5\%), Late Clinical Failure (LCF) of 19 (11.6\%), Late Parasitological Failure (LPF) of 39 (23.8\%) and Earlier Treatment Failure (ETF) of 56 (34.1). Quinine was the second most used drug of choice with a preference rate of 27 (13.9\%). The study recorded an ACPR of $3(11.1 \%)$, LCF of $3(11.1 \%)$, LPF of 4 (14.8\%) and ETF of $17(63 \%)$ for the participants who were given Quinine as a treatment drug. Fansidar was the least preferred antimalarial drug with a preference rate of $3(1.5 \%)$. Finally, the study recorded an ACPR of 0 $(0 \%)$, LCF of $1(33.3 \%)$, LPF of $0(0 \%)$ and ETF of $2(66.7 \%)$ respectively for the participants who were treated by using Fansidar (Table 2).

Majority of the participants $(n=100 ; 51.5 \%)$ received the recommendations on the type of drug to use by a medical doctor while $57(29.4 \%)$ received recommendation from the nurse. Self-medication was practiced by less percentage of participants at 37 (19.1\%). In relation to treatment responses, those who were recommended by a doctor experienced more ACPR at 32 (32\%) while those whose recommendation was from a nurse the ACPR was 14 (24.6\%) and second most ETF at 9(24.3\%). Moreover, those who practiced self-medication experienced the least ACPR at 7 (18.9\%). The study indicated that those who received the drugs as a result of the doctor's recommendation had the highest ETF at $42(42 \%)$ and those who practiced self-medication had the lowest ETF at 9 (24.5\%)(Table 2).

Majority of the participants purchased the drugs from a health care facility at $119(61.3 \%)$ followed by chemist (drug-shop) at $39(20.1 \%)$ and pharmacy shop at $35(18 \%)$. Those who obtained the drugs from friends were the least at $1(0.5 \%)$. The study found that those who purchased the drugs from the hospital had the highest percentage of ACPR at $(28.6 \% ; n=34)$ compared with those who purchased from pharmacy at $9(25.7 \%)$ and chemist at $9(23.1 \%)$ (Table 2).

The study reported that $130(67 \%)$ of the participants were able to finish the recommended dose and those who were unable to finish the dose were 64 (33.0\%). Out of those who completed the dose, $60(46.2 \%)$ developed ETF compared to 15 (23.4\%) of those who did not complete the dose. Further, out of those who completed the dose, 33 (25.4\%) developed ACPR, compared to 20 (31.2\%) of those who did not complete the dose. The study revealed that $103(53.1 \%)$ of the participants experienced malaria infections twice a year, 46 $(23.7 \%)$ once a year, $42(21.6 \%)$ once in three months and $3(1.5 \%)$ of the participants experienced the infection once in a month. The study reported that 32 (31.1\%) of the participants who experienced malaria 
infections twice a year developed ACPR compared to ACPR of 1 (33.3\%) for those who experienced malaria infections once in a month (Table 2).

The study revealed that the highest percentage $(51 \%, n=99)$ used anti-malarial drugs as recommended in the health care facility, 4 (2.1\%) used anti- malaria drugs once a in a while and $91(46.9 \%)$ of the population used anti-malaria drugs any time they felt feverish. It was found out that ACPR was highest $(n=30,30.3 \%)$ among those who used the drugs as recommended in the health care facility compared to $24.2 \%(n=22)$ of those who used anti-malaria drugs anytime they felt feverish and $1(25 \%)$ among those who used the drugs once in a while (Table 2).

\section{Malaria control practices associated with treatment outcomes}

The study revealed that $66(78.6 \%)$ of the participants obtained the indoor spraying from the government compared to 4 (22.2\%) who self-sourced. Indoor residual spraying at home was practiced by $82(42.3 \%)$ of the participants was shown to have a statistically significant $(P=0.004)$ influence on treatment outcome compared to the $57.7 \%(n=112)$ who did not practice indoor spraying. The highest ACPR was recorded at 38 $(33.9 \%)$ among those who did not practice indoor spraying compared to $10(18.3 \%)$ who practiced indoor spraying. Similarly, the study reported highest ETF of 44 (53.7\%) among those who practiced indoor spraying compared to $31(27.7 \%)$ of those who did not. Those who had sprayed their homes not more than 6 months prior to this study represented $19(22.9 \%)$ of the participants compared to $64(77.1 \%)$ participants who had sprayed their homes in more than 6 months prior to this study. Only $2(10.5 \%)$ of the participants who had sprayed their homes in not more than 6 months developed ACPR compared to $14(21.9 \%)$ among the participants who had sprayed their homes in more than 6 months. However, those who sprayed their homes in more than 6 months experienced the lowest percentage of ETF $51.6 \%$ compared to $57.9 \%$ of those who had sprayed their homes in not more than 6 months. Overall, the influence of sleeping under a mosquito net upon the treatment outcome was statistically significant $(P=0.015)$. Consequently, it was reported that out of those who slept under an ITN, 49 (30.2\%) developed ACPR compared to 4 (12.5\%) among those who did not sleep under the mosquito net. Moreover, those who slept under an ITN developed ETF of $65(40.1 \%)$ compared to 10 (31.2\%) for those participants who did not. However, 73(45.1\%) slept under ITN while 89 (54.9\%) did not sleep under ITN. The study found out that $23(31.5 \%)$ of the participants who slept under ITN developed ACPR compared to 26 (29.2\%) for those who did not sleep under ITN. The highest number of the participants obtained the mosquito nets from the government facility at 90 (56.2\%), compared to the lowest number of $6(3.7 \%)$ who reported to have obtained the mosquito nets from malaria campaign. On the environmental front, most of the participants reported to have vegetation such as bananas near their homesteads at $159(82.0 \%)$ compared to $35(18.0 \%)$ who didn't have vegetation near their homesteads. In relation to the occurrence of stagnant water near the homesteads, $108(55.7 \%)$ of the participants reported to have stagnant water compared to $86(44.3 \%)$ who didn't have stagnant water (Table $3)$.

\section{Multivariate regression analysis of predisposing factors associated with treatment outcomes}

Multinomial regression model was used in bivariate analysis to obtain crude odds for the strength of association between influencing factors (malaria treatment practices and malaria control interventions) on 
malaria treatment outcomes. Factors that were statistically significant $(p \leq 0.05)$ at bivariate analysis, were included in the multivariate analysis. The model was checked for best fit of data and then used to compute adjusted odds ratios of factors that were associated with malaria treatment outcomes. Statistical significance was considered at $95 \%$ level of confidence (Table 4 ).

\section{Discussion}

Malaria treatment and control practices have been generally implicated in the overall reduction of clinical episodes across the world though the exact reduction rate is unknown. The Ugandan government has currently scaled out different intervention programs to combat malaria infection. Despite the efforts being embraced, there still remains huge percentage of mortalities and morbidities caused by the disease. Many studies have been carried across the world and Uganda to determine the usage of different malaria intervention practices on the occurrence of malaria $[21 ; 22 ; 23 ; 24]$. This study assessed the impact of malaria intervention practices on malaria treatment outcomes on patients treated with ACTs, the first study of its kind to be conducted in Bushenyi District in Western Uganda. The development and spread of resistance to previously used anti-malarial drugs (sulfadoxine-pyrimethamine,and chloroquine) has prompted Uganda to adopt a new malaria control policy based on three major interventions: vector control with long lasting insecticide-treated nets (LLINs), the use of artemisinin-based combination therapy (ACT) for treating uncomplicated malaria; and chemoprophylaxis for pregnant women [25].

Among all control measures that are used against the malaria spread, chemotherapeutic agents seem to contribute largely to the strategy of combating malaria mortality in the world. Quinoline derivatives and antifolates were the first mainstream malaria agents in the world; however, resistance has been reported in some parts of the world $[26 ; 27 ; 28]$. Currently they are recommended for use as malaria prophylactic agents in infants and pregnant mothers [29]. Presently the World Health Organization (WHO) recommends artemisinin-based combination therapies (ACTs) for the treatment of uncomplicated malaria in most countries particularly where resistance has developed towards other drugs. Uganda adopted the use of artemether-lumefantrine (AL) as the drug of choice for treatment of uncomplicated malaria, however the actual implementation started in 2006 [30]. The current study reported the highest participants adopting ACTs for malaria treatment at $84.5 \%$ which is in agreement with other previous studies done in Africa [31; $32 ; 33]$. This could be attributed to the fact that ACTs are provided free of charge by the governments in the study sites. The high prevalence for ACTs usage might have been because it is the first line therapy for uncomplicated malaria in Uganda. Moreover, it is mostly available in public health facilities. The low level use of fansidar observed in this study could be due to the fact that it is recommended by Ministry of Health for prophylaxis majorly to pregnant women and at the same time it is not available in most health facilities.

The present study recorded the highest ACPR (30.5\%) among participants who used ACTs. This is not surprising since ACTs are currently recommended by WHO and adopted by the Ugandan government as the first line treatment regimen for uncomplicated malaria. This finding is in agreement with a previous study conducted in Gulu district of Northern Uganda [34] which recorded ACPR of 95.2\% with all participants being negative for parasites at day 2 of the follow up after treatment with ACTs. The study conducted in Tororo district of Eastern Uganda reported an ACPR prevalence of $40 \%$ among the participants [35]. Another study 
conducted at Tororo district recorded an ACPR prevalence of 50\% [36] while similar study conducted at Gulu district of Northern Uganda recorded an ACPR prevalence of $42 \%$ among the participants [37]. Our study recorded high ACPR among participants who obtained the anti-malaria drugs from the hospital compared with those obtaining from the pharmacy or chemist. This could be because health practitioners in the hospital settings prescribe antimalarial drugs in relation to laboratory results. Furthermore, patients can purchase antimalarial drugs directly from the pharmacies and chemists without any medical prescription. The rate of self-medication practice was found to be $19.1 \%$ which was low compared to other studies. For example a study conducted in northern Uganda, a geographical area of high malaria transmission intensity reported slightly at a higher prevalence of $36.2 \%$ self-medications among the study population [38].

Moreover, it has been previously reported in a study done in Apac, northern Uganda that $75.7 \%$ of adult ( $\geq 18$ years) community members accessed and used antimicrobial drugs generally without taking a laboratory test and nor a prescription from health care providers [39]. The probable reason for the reduced selfmedication might be because of the current scaling of free malaria treatment offered by the government of Uganda and the availability of many health facilities across the district. The low self-medications reported in the current study area might also be due to the fact that majority of the population have access to health facilities which are located not more than ten kilometers. Another study conducted in Nigeria reported a high percentage of $33.7 \%$ for self-medication compared to $17.4 \%$ for doctor recommendations and $12.5 \%$ for nurse recommendation [40]. Anti-malaria drug use pattern influences the development and spread of resistance in the community due to continued sub-optimal use of the drugs. Self-medication uses treatment without any diagnosis and this has been implicated in the anti-malaria resistance [41; 42]. Appropriate use of the correct prescribed dose is an important factor in malaria treatment. From the current study, $31.2 \%$ of the participants did not complete their prescribed doses while $67 \%$ completed the prescribed anti-malaria doses in the recent malaria illness. These findings are contrary to those from other studies such as one that was carried out in Bangladesh which reported that $68 \%$ of the participants did not complete the treatment doses because patients would stop taking medications as soon as they would feel well [43]. Failure to complete treatment doses leads to sub-therapeutic drug levels in patient blood which encourages selection for resistant parasites and treatment failure [44].

The current study recorded a substantially low usage of indoor residual spraying at $42.3 \%$. Contrary to previous findings by Uganda demographic health survey [45] which found out $67.2 \%$ of the population was using IRS. However, it was established that majority of the participants (78.6\%) used government to access the IRS. This is because currently the government of Uganda has scaled out nationwide IRS in all households present in the high malaria transmission areas [46] In 2012, 88 countries in Africa were implementing IRS, and the number of people protected by IRS increased from $5 \%$ of those at risk in 2005 to $11 \%$ in 2010 , but fell to $8 \%$ in 2012 . Our study has shown significant reduction by IRS on the occurrence of parasitemia after treatment with anti-malaria drugs. This is in agreement with other studies conducted elsewhere in Uganda $[47 ; 48 ; 49 ; 50]$, as well as in other studies conducted outside Uganda [51;52].

In 2007, WHO recommended universal coverage for ITNs use by all persons in all households [53]. The present study found out that $83.5 \%$ of the participants slept under mosquito nets. This may be due to the fact that the government of Uganda has distributed free nets in previous years as well as the continued malaria campaigns that have been taking place. But surprisingly only $45.1 \%$ of those who owned nets were 
insecticides treated nets (ITNs). These findings are in contrast to a study which showed that $54 \%$ of African households owned at least one ITN and only $36 \%$ of the population slept under ITNs (54). According to the Uganda Demographic Health Survey done in $2018 / 2019,83 \%$ of the total population was in possession of at least an ITN per house hold [55]. West Nile region had the highest possession of ITNs at $92 \%$, with Karamoja region at $58 \%$ and Ankole region where the current study area is located at $86 \%$.Our findings did not show any significant difference on the protective effect against malaria between ITNs and noninsecticides treated nets. The results however, showed that sleeping under any type of net reduced the rate of malaria occurrence after treatment with anti-malarial agents. Our findings are in agreement with a study conducted in Uganda from 2009 to 2014 which showed a strong ITNs effect on parasitaemia risk reduction [56]. Other studies done outside Uganda also reported similar trends on usage of ITNs in the reduction of malaria incidences $[57 ; 58 ; 59 ; 60]$. In relation to the influence of ITNs on treatment outcomes, our study recorded an ACPR of $30.2 \%$ which disagrees with previous studies conducted outside Uganda that recorded lower ACPR. For example, a study conducted in Tanzania among malaria positive pregnant women recorded a $6 \%$ prevalence of ACPR [61]. Other related studies have also reported lower ACPR among the participants at $9.1 \%$ [62]. However, our study is in agreement with some previous studies which recorded a higher prevalence of ACPR of $42 \%[63 ; 64]$. The outcomes of treatment in relation to the intervention measures might have been influenced by other factors such as genetic, immunological and pharmacokinetic factors not assessed by this study.

\section{Conclusion}

This study has demonstrated that two major malaria control interventions i.e. IRS and ITNs had a positive impact on reducing of parasitaemia risk after treatment of patients with antimalaria drugs.

\section{Recommendation}

We hereby recommend that the government of Uganda with other private sectors need to increase the universal ITN and IRS coverage. Uganda Ministry of Health should promote malaria prevention awareness campaigns so as to educate the public about the importance of ITNs and IRS even after being treated with drugs. ITNs and IRS should be integrated together with ACTs in patients under malaria treatment so as to prevent future malaria occurrences. In addition we recommend that more studies covering larger geographical regions should be conducted in Uganda.

\section{Abbreviations}

IPTp: intermittent preventive treatment in pregnancy; NMCP: National Malaria Control Program; UDHS: Uganda Demographic and Health Survey; UMIS: Uganda Malaria Indicator; SP: sulfadoxine-pyrimethamine; WHO: World Health Organization; ITNs: insecticide treated nets; IRs: indoor residual spray; AL: artemeter lumefantrine; ACTs: artemisinin combined therapies; ACPR: adequate clinical and parasitological response; LPF: late parasitological failure; LCF: late clinical failure; ETF: early treatment failure.

\section{Declarations}




\section{Acknowledgments}

We hereby thank the entire clinical staff of Kampala International University-Teaching Hospital (KIU-TH), Ishaka Adventist Hospital, Kyeizooba health centre III and Kyamuhunga health centre III for their technical assistance. We are grateful to the participants and the parents or guardians who kindly provided consent for this study. We also thank the village health officers who helped our study team during the follow up of the participants and the entire team members involved in data collection at the four health centers.

\section{Funding}

This study was solely funded by the authors.

\section{Data Availability}

Data in tables used to support the findings of this study are included within the article.

\section{Authors' Contributions}

This work was carried out in collaboration between all authors. Authors JNM, ADK, and MCM designed the study, managed literature review, performed the statistical analysis, wrote the protocol, and wrote the first draft of the manuscript and proof reading of the final draft. All Authors managed the analyses of the study, proof read the first draft of the manuscript and performed the statistical analysis. All authors read and approved the final manuscript.

\section{Competing interest}

All authors declare that there are no conflicts of interest existing in regard to this study and publication of the findings.

\section{Consent for publication}

Not applicable

\section{Ethics approval and consent to participate}

The ethical approval of the study was sought from Mbarara University of Science and Technology (MUST) Institutional Research and Ethics Committee (IREC) on Human Research (Approval no 06/01-17) and Uganda National Council for Science and Technology (Approval no HS2241). All research protocols were performed in accordance with the ethical standards of the committees on human experimentation laid down in the Helsinki declaration of 1975 as revised in 2000.

\section{References}

1. WHO, Guidelines for the treatment of malaria (third edition), Geneva: 2015. World Health Organization; 2015. 
2. Oguoma VM and Ikpeze 00. Species composition and abundance of mosquitoes of a tropical irrigation ecosystem. Animal Research International.2008; 5: 866.

3. WHO, Global Malaria Programme. World malaria report 2019. Geneva: World Health Organization; 2019.

4. WHO, Guidelines for the treatment of malaria (third edition), Geneva: 2018. World Health Organization; 2018.

5. Barat LM, Palmer N, Basu S, Worrall E,.Hanson K. Do malaria control interventions reach poor. Am J Trop Med Hyg. 2014; 71: 174.

6. WHO, Guidelines for the treatment of malaria (third edition), Geneva: 2016. World Health Organization; 2016

7. Bhatt S, Weiss DJ, Cameron E, Bisanzio D, Mappin B, Dalrymple U, et al. The effect of malaria control on Plasmodium falciparum in Africa between 2000 and 2015. Nature. 2015; 526:207.

8. Uganda Bureau of Statistics (UBOS) and ICF International. Uganda malaria indicator survey 2014-15. Kampala, Uganda, and Rockville, Maryland, USA: UBOS and ICF International; 2015. [Internet]. Https: //dhspr ogram .com/pubs/pdf/mis21/mis21 .pdf. Accessed 26 Sept 2018.

9. Ramphul U, Boase T, Bass C, Okedi LM, Donnelly MJ, Müller P. Insecticide resistance and its association with target-site mutations in natural populations of Anopheles gambiae from eastern Uganda. Trans $\mathrm{R}$ Soc Trop Med Hyg. 2009; 11:1121.

10. Takem EN, D’Alessandro U. Malaria in pregnancy. Mediterr J Hematol Infect Dis. 2013; 5:201.

11. WHO, Global Malaria Programme. World malaria report 2017. Geneva: World Health Organization; 2017.

12. Okethwangu D, Opigo J, Atugonza S, Catherine T. Kizza R, Nabatanzi M, et al. Factors associated with uptake of optimal doses of intermittent preventive treatment for malaria among pregnant women in Uganda: analysis of data from the Uganda Demographic and Health Survey, 2016 Malar J.2019; 18:250.

13. Uganda Bureau of Statistics (UBOS) and ICF International. Uganda malaria indicator survey 2014-15. Kampala, Uganda, and Rockville, Maryland, USA: UBOS and ICF International; 2015. [Internet]. Https : //dhspr ogram .com/pubs/pdf/mis21/mis21 .pdf. Accessed 26 Sept 2018.

14. Okello PE,Van BW, Byarunga AM, Correwyn A, Roelants P, Talisuna A, et al. Varriation in malaria transmission intensity in seven sites throught Uganda. AM J TRPO Med Hyg. 2006, 75:219.

15. Uganda ministry of health (UMH). Uganda Malaria Annual Report July 2017-June 2018; 2018.

16. Uganda Bureau of Statistics (UBOS). Health planning in Uganda; 2015.

17. Uganda Bureau of Statistics (UBOS). Uganda demographic and health survey 2014/2015. 2015.

18. Uganda Malaria Indicator Survey. (2014-15). Kampala, Uganda, and Rockville, Maryland, USA: UBOS and ICF International; 2015.

19. Maniga JN, Aliero AA, Ibrahim N, Okech MA and Mugasa CM.Plasmodium falciparum Malaria Clinical and Parasitological Outcomes after In-vivo Artemether- Lumefantrine (AL) Treatment at Bushenyi District Uganda. International Journal of TROPICAL DISEASE\& Health. 2018; 29: 1.

20. WHO,.Assessment and monitoring of antimalarial drug efficacy for the treatment of uncomplicated falciparum malaria. Geneva; 2003. 
21. Ssemplira J, Nambuusi B, Kissa J, Agaba B, Makumbi F, Kasasa S and Vounatsou P. The contribution of malaria control interventions on spatio- temporal changes of parasitaemia risk in Uganda during 20092014. Parasites and vectors. 2017; 510:450.

22. Ministry of Health. The Uganda Malaria Reduction Strategic Plan 2014-2020. Kampala: Ministry of Health; 2014.

23. National Malaria Control Program. Uganda Malaria Operational Plan. 2016. Available:https://www.pmi.gov/docs/default-source/default-documentlibrary/malaria-operationalplans/fy 16/fy-2016-uganda-malaria-operationalplan.pdf?sfvrsn=5

24. Louis VR, Bals J, Tiendrebéogo J, Bountogo M, RamrothH, Allegri MD, et al. Long-term effects of malaria prevention with insecticide-treated mosquito nets on morbidity and mortality in African children: randomized controlled trial. Tropical Med Int Health.2012; 17:733.

25. Ssempiira J, Nambuusi B, Kissa J, Agaba B, Makumbi F, Kasasa S, et al. The contribution of malaria control interventions on spatio-temporal changes of parasitaemia risk in Uganda during 2009-2014. Parasite Vectors. 2017; 10:450.

26. Roper C, Pearce R, Nair S, Sharp B, Nosten F, Anderson T.Antifolate antimalarial resistance in southeast Africa: a population-based analysis. Lancet. 2003; 361: 1174.

27. Nair A. A selective sweep driven by pyrimethamine treatment in south East Asian malaria parasites. MolBiolEvol.2003; 20:1526-36.

28. Davis TM, Hung TY, Sim IK, Karunajeewa HA, llett KF.Piperaquine: a resurgent antimalarial drug. Drugs Journal. 2005; 65: 75.

29. WHO, Global Malaria Programme. World malaria report 2015. Geneva: World Health Organization; 2015.

30. Nanyunja M, Nabyonga JO, Kato F, Kaggwa M, Katureebe C, Saweka C.Malaria treatment policy change and implementation: the case of Uganda. Malar Res Treat.2011; 2168:167.

31. Okeke TA, Uzochukwu B, Okafor H. An in-depth study of patent medicine sellers' perspectives on malaria in a rural Nigerian community.Malar J. 2006; 5:97.

32. Allilio MS, Kamugisha ML, Msuya FK, Massaga JL, Salum FM, Njunwa KJ. Availability and utilization of anti-malarial drugs at community level in Same district, North Eastern Tanzania. Malar Infect Dis Africa. 1997; 15:28.

33. Sirima SB, Gansane A. Artesunate-amodiaquine for the treatment of uncomplicated malaria. Expert Opin Investig Drugs. 2007; 16:1079.

34. Balikagala B, Toshihiro M, Ikeda M, Sakurai M, Yatsushiro S, Takahashi N, et al. Absence of in-vivo selection for K13 mutations after artemether-Lumefantrine treatment in Uganda. Malaria Journal. 2017; 8: 16.

35. Muhindo K, Kakuru1 A, Jagannathan P,Talisuna A, Osilo E, Orukan F,Arinaitwe E, Tappero W, Kaharuza F, Kamya $\mathrm{M}$ andDorsey $\mathrm{G}$. Early parasite clearance following artemisinin based combination therapy among Ugandan children with uncomplicated Plasmodium falciparum malaria. Malaria journal. 2014; 13: $32-40$. 
36. Bukirwa H, Yeka A, Kamya MR, Talisuna A, Banek K, Bakyaita N, et al. Artemisinin Combination therapies for treatment of uncomplicated malaria in Uganda. PLoSCInTrials.2006; 8: 38.

37. Yeka A, Dorsey G, Kamya MR, Talisuna A, Lugemwa M, et al. Artemether-lumefantrine versus dihydroartemisinin-piperaquine for treating uncomplicated malaria: a randomized trial to guide policy in Uganda. PLoS One. 2008; 3:1371.

38. Ocan M, Bwanga F, Bhosa GS, Bagenda D, Waako P, Okeng JO, Obua C. Patterns and predictors of selfmedication in northern Uganda. PLoS ONE.2014; 9: 9-23.

39. Kamya MR, Yeka A, Bukirwa H, Lugemwa M, Rwakimari JB, et al. Artemether-lumefantrine versus dihydroartemisinin-piperaquine for treatment of malaria: A randomized trial. PLoS Clin Trials.2007; 2: 20.

40. Omole MK, and Onademuren OT. A survey of antimalarial drug use practices among urban dwellers in Abeokuta, Nigeria. African Journal of Biomedical Research.2010; 4:1- 7.

41. Akello G.Wartime children's' suffering and quests for therapy in northern Uganda. African studies center Netherlands. 2010; 35: 15.

42. Thang ND, Erhart A, Speybroeck N, Hung IX, ThuanIK. Malaria in central Vietnam: analysis of risk factors by multivariate analysis and classification tree models. Malar J.2008; 7:28.

43. Sultana F, Rahman A, Rani PT, Sarwir S, Islam AU and Rashid M. Prescribing pattern and prescription Errors: A study at a tertiary care hospital of Bangladesh. Bangladesh pharmaceutical journal.2015; 18: 20.

44. Oshikoya AK. Antimalarial Prescriptions for Children Presenting with Uncomplicated Malaria to a Teaching Hospital in Nigeria after a change of National Guidelines for Malaria Treatment. World Journal of Medical Sciences.2007; 2: 49.

45. Uganda Bureau of Statistics (UBOS) and ICF International. Uganda malaria indicator survey 2014-15. Kampala, Uganda, and Rockville, Maryland, USA: UBOS and ICF International; 2015. https://dhspr ogram .com/pubs/pdf/mis21/mis21 .pdf. Accessed 26 Sept 2018.

46. National Malaria Control Program. Uganda Malaria Operational Plan. 2016. Available:https://www.pmi.gov/docs/default-source/default-documentlibrary/malaria-operationalplans/fy16/fy-2016-uganda-malaria-operationalplan.

47. Kigozi R, Baxi SM, Gasasira A, Sserwanga A, Kakeeto S, Nasr S, et al. Indoor residual spraying of insecticide and malaria morbidity in a high transmission intensity area of Uganda. PLoS One.2012; 7:428.

48. Ssemplira J, Nambuusi B, Kissa J, Agaba B, Makumbi F, Kasasa S, Vounatsou P. The contribution of malaria control interventions on spatio- temporal changes of parasitaemia risk in Uganda during 20092014. Parasites and vectors. 2017; 510-450.

49. Kamya MR, Arinaitwe E, Wanzira H, Katureebe A, Barusya C, Kigozi SP, et al. Malaria transmission, infection, and disease at three sites with varied transmission intensity in Uganda: implications for malaria control. Am J Trop Med Hyg.2015; 92: 903.

50. Okwaro FM, Chandler Cl, Hutchinson E, Nabirye C, Taaka L, Kayendeke M, et al. Challenging logics of complex intervention trials: community perspectives of a health care improvement intervention in rural 
Uganda. Soc Sci Med. 2015; 131: 10.

51. Kleinschmidt I, Schwabe C, Shiva M, Segura JL, Sima V, Mabunda SJ, et al. Combining indoor residual spraying and insecticide-treated net interventions. Am J Trop.2015; 23-34.

52. Zhou G, Munga S, Minakawa N, Githeko AK, Yan G. Spatial relationship between adult malaria vector abundance and environmental factors in Western Kenya highlands,Am J Trop Med Hyg.2014;77: 29.

53. World Health Organization. Everybody's Business: Strengthening Health Systems to Improve Health Outcomes: WHO's Framework for Action. 2007. Available at: http://www.who.int/healthsystems/ strategy/everybodys_business.pdf.Accessed February 1, 2016.

54. Bhatt S, Weiss DJ, Cameron E, Bisanzio D, Mappin B, Dalrymple U, et al. The effect of malaria control on Plasmodium falciparum in Africa between 2000 and 2015.Nature. 2015; 526:207.

55. Uganda National Malaria Control Division (NMCD), Uganda Bureau of Statistics (UBOS), and ICF. 2019. 2018-19 Uganda Malaria Indicator Survey Atlas of Key Indicators. Kampala, Uganda, and Rockville, Maryland, USA: NMCD, UBOS, and ICF.

56. Semplira JS, Nambuusi B, Kissa J, Agaba B, Makumbi F, Kasasa S, et al. The contribution of malaria control interventions on spatio- temporal changes of parasitaemia risk in Uganda during 2009-2014. Parasites and vectors.2017; 5:10.

57. Wanzira H, Yeka A, Kigozi R .Long-lasting insecticide-treated bed net ownership and use among children under five years of age following a targeted distribution in central Uganda. Malaria Journal. 2014; 185 : 14.

58. Muhumuza E, Namuhani N, Balugaba BE, Namata J, Kiracho EE. Factors associated with use of malaria control interventions by pregnant women in Buwunga subcounty, Bugiri District. Malar J. 2016; $15: 342$.

59. Taremwa IM, Ashaba S, Adrama HO, Ayebazibwe C, Omoding D, Kemeza I, et al. Knowledge, attitude and behaviour towards the use of insecticide treated mosquito nets among pregnant women and children in rural Southwestern Uganda. BMC Public Health. 2017; 17:794-99.

60. Ahmed SM, Zerihun A. Possession and usage of insecticidal bed nets among the people of Uganda: is BRAC Uganda Health Programme pursuing a pro-poor path? PLoS One. 2010; 5:126.

61. Mutagonda RF, Kamuhabwa AR, Omary MS, Massawe NS, Betty AM, et al. Malaria prevalence, severity and treatment outcome in relation to day 7 lumefantrine plasma concentration in pregnant women. Malaria Journal. 2016; 15:278.

62. Nega D, Dana D, Tefera T, Eshetu T. Prevalence and predictors of asymptomatic malaria parasitemia among pregnant women in the rural surroundings of Arbaminch Town, South Ethiopia. PLoS One. 2015; $10: 12$.

63. Gunn JK, Ehiri JE, Jacobs ET, Ernst KC, Pettygrove S, Kohler LN, et al. Population-based prevalence of malaria among pregnant women in Enugu State, Nigeria: the healthy beginning initiative. Malar J. 2015; $14: 4$.

64. Cisse M, Sangare I, Lougue G, Bamba S, Bayane D, Guiguemde RT. Prevalence and risk factors for Plasmodium falciparum malaria in pregnant women attending antenatal clinic in Bobo-Dioulasso (Burkina Faso). BMC Infect Dis. 2014; 14:6.

Page $15 / 24$ 


\section{Tables}

Table 1. Socio-demographic baseline characteristics of participants

Location in main text: page 9, after line 185 


\begin{tabular}{|c|c|}
\hline Variable & Number of participants (n/\%) \\
\hline \multicolumn{2}{|l|}{ Age (years) } \\
\hline $0-5$ & $3(1.5)$ \\
\hline $6-18$ & $76(39.2)$ \\
\hline$>18$ & $115(59.3)$ \\
\hline \multicolumn{2}{|l|}{ Gender } \\
\hline Female & $104(53.6)$ \\
\hline Male & $90(46.4)$ \\
\hline \multicolumn{2}{|l|}{ Weight (kg) } \\
\hline 0-10 & $1(0.5)$ \\
\hline $11-20$ & $5(2.6)$ \\
\hline $21-30$ & $21(10.8)$ \\
\hline$\geq 31$ & $167(86.1)$ \\
\hline \multicolumn{2}{|l|}{ Marital status } \\
\hline Single & $104(53.6)$ \\
\hline Married & $90(46.4)$ \\
\hline \multicolumn{2}{|l|}{ Education level } \\
\hline None & $4(2.1)$ \\
\hline Primary & $107(55.2)$ \\
\hline Secondary & $50(25.8)$ \\
\hline University/college & $7(33)$ \\
\hline \multicolumn{2}{|l|}{ Occupation } \\
\hline None & $3(1.5)$ \\
\hline Student/pupil & $84(43.3)$ \\
\hline Casual worker & $14(7.2$ \\
\hline Business & $23(11.9$ \\
\hline Peasant farmer & $53(27.3$ \\
\hline House wife & $5(2.6)$ \\
\hline Formal employment & $10(5.2)$ \\
\hline Others & $2(1.0)$ \\
\hline
\end{tabular}




\begin{tabular}{|ll|}
\hline$<5$ & \\
\hline $5-10$ & $13(22.2)$ \\
\hline$>10$ & $12(6.2)$ \\
\hline Hospital attended & \\
\hline Kyamuhunga HC III & $42(21.6)$ \\
\hline KIUTeachingHospital & $71(36.6)$ \\
\hline Kyeizooba HC III & $71(36.6)$ \\
\hline Ishaka Adventist Hospital & $10(5.2)$ \\
\hline Total & $194(100)$ \\
\hline
\end{tabular}

Table 2: Bivariate analysis of malaria treatment practices associated with treatment outcomes Location in main text: page 10, after line 204 


\begin{tabular}{|c|c|c|c|c|c|c|c|}
\hline Variable & & Treatment & Outcomes & $n(\%)$ & & & \\
\hline & $\begin{array}{l}\text { Number of } \\
\text { participants, } \\
\mathrm{N}(\%)\end{array}$ & $\begin{array}{l}\text { ACPR } \\
(n=53)\end{array}$ & $\begin{array}{l}\text { LCF } \\
(n=23)\end{array}$ & $\begin{array}{l}\text { LPF } \\
(n=43)\end{array}$ & $\begin{array}{l}\text { ETF } \\
(n=75)\end{array}$ & $\begin{array}{l}\text { COR } \\
(95 \% \\
\text { Cl) }\end{array}$ & $\begin{array}{l}\mathrm{P}- \\
\text { value }\end{array}$ \\
\hline \multicolumn{8}{|l|}{$\begin{array}{l}\text { Antimalarial } \\
\text { used }\end{array}$} \\
\hline ACT & $164(84.5)$ & $50(30.5)$ & 19(11.6) & $39(23.8)$ & $56(34.1)$ & $\begin{array}{l}0.679 \\
(0.058- \\
7.913)\end{array}$ & 0.757 \\
\hline Quinine & $27(13.9)$ & $3(11.1)$ & $3(11.1)$ & $4(14.8)$ & 17(63.0) & $\begin{array}{l}0.353 \\
(0.042- \\
5.231)\end{array}$ & 0.449 \\
\hline Fansider & $3(1.5)$ & 0 & $1(33.3)$ & 0 & $2(66.7)$ & 1.000 & \\
\hline \multicolumn{8}{|l|}{$\begin{array}{l}\text { Source of } \\
\text { antimalarial } \\
\text { recommendation }\end{array}$} \\
\hline Doctor & $100(51.5)$ & $32(32.0)$ & 10(10.0) & 16(16.0) & $42(42.0)$ & $\begin{array}{l}0.286 \\
(0.101- \\
0.807)\end{array}$ & $0.018 *$ \\
\hline Nurse & $57(29.4)$ & $14(24.6)$ & $4(7.0)$ & 15(26.3) & $24(42.1)$ & $\begin{array}{l}0.469 \\
(0.159- \\
1.378)\end{array}$ & 0.169 \\
\hline Self-medication & $37(19.1)$ & $7(18.9)$ & $9(24.3)$ & $12(32.4)$ & $9(24.3)$ & 1.000 & \\
\hline \multicolumn{8}{|l|}{$\begin{array}{l}\text { Source of } \\
\text { antimalarial } \\
\text { drugs }\end{array}$} \\
\hline $\begin{array}{l}\text { Health care } \\
\text { facility }\end{array}$ & 119(61.3) & $34(28.6)$ & $8(6.7)$ & $26(21.8)$ & $51(42.9)$ & $\begin{array}{l}0.889 \\
(0.350- \\
2.257)\end{array}$ & 0.805 \\
\hline Pharmacy shop & $35(18.0)$ & $9(25.7)$ & $9(25.7)$ & $4(1.4)$ & 13(37.1) & $\begin{array}{l}0.537 \\
(0.135- \\
2.130)\end{array}$ & 0.376 \\
\hline Chemist & $39(20.1)$ & $9(23.1)$ & $6(15.4)$ & 13(33.3) & $11(28.2)$ & - & - \\
\hline Friends & $1(0.5)$ & $1(100)$ & 0 & 0 & 0 & 1.000 & \\
\hline \multicolumn{8}{|l|}{$\begin{array}{l}\text { Ability of } \\
\text { finishing dose }\end{array}$} \\
\hline Yes & $130(67.0)$ & $33(25.4)$ & 13(10.0) & $24(18.5)$ & $60(46.2)$ & $\begin{array}{l}0.316 \\
(0.138- \\
0.721)\end{array}$ & $0.006^{\star}$ \\
\hline No & 64(33.0) & $20(31.2)$ & $10(15.6)$ & $19(29.7)$ & $15(23.4)$ & 1.000 & \\
\hline
\end{tabular}


prescribed dose

\begin{tabular}{|c|c|c|c|c|c|c|c|}
\hline $\begin{array}{l}\text { When I feel } \\
\text { healed }\end{array}$ & $66(34.0)$ & 21(31.8) & $10(15.2)$ & $20(30.3)$ & $15(22.7)$ & $\begin{array}{l}3.478 \\
(0.170- \\
1.203)\end{array}$ & $0.003^{\star}$ \\
\hline $\begin{array}{l}\text { When I complete } \\
\text { dose }\end{array}$ & $128(66.0)$ & $32(25.0)$ & 13(10.2) & 23(18.0) & $60(46.9)$ & 1.000 & \\
\hline
\end{tabular}

\section{Frequency of \\ malaria infection \\ per year}

\begin{tabular}{llllllll} 
Once in a month & $3(1.5)$ & $1(33.3)$ & 0 & 0 & 0 & - & - \\
$\begin{array}{l}\text { Once in 3 } \\
\text { months }\end{array}$ & $42(21.6)$ & $11(26.2)$ & $4(9.5)$ & $8(19.0)$ & $19(45.2)$ & & \\
\hline Once in a year & $46(23.7)$ & $9(19.6)$ & $4(8.7)$ & $8(17.4)$ & $25(54.3)$ & $\begin{array}{l}0.344 \\
(0.133-\end{array}$ & $0.028^{*}$ \\
& & & & & & $\begin{array}{l}0.892) \\
\end{array}$
\end{tabular}

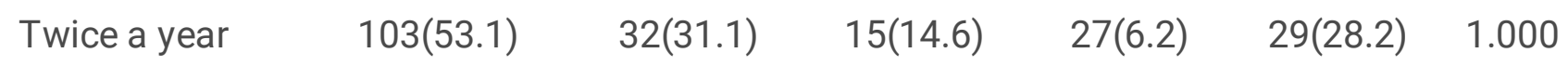

\section{Frequency of antimalarial drug use}

\begin{tabular}{|llllllll|}
\hline Once in a while & $4(2.1)$ & $1(25.0)$ & $1(25.0)$ & $2(50.0)$ & 0 & - & - \\
\hline $\begin{array}{l}\text { Anytime I feel } \\
\text { feverish }\end{array}$ & $91(46.9)$ & $22(24.2)$ & $16(17.6)$ & $24(26.4)$ & $29(31.9)$ & $\begin{array}{l}2.239 \\
1.031-\end{array}$ & $0.042^{*}$ \\
\hline $\begin{array}{l}\text { As } \\
\text { recommended in } \\
\text { health care } \\
\text { facility }\end{array}$ & $99(51.0)$ & $30(30.3)$ & $6(6.1)$ & $17(17.2)$ & $46(46.5)$ & 1.000 & \\
\hline $\begin{array}{l}\text { Distance to } \\
\text { health facility }\end{array}$ & & & & & & & \\
\hline$<1 \mathrm{~km}$ & $48(24.7)$ & $13(27.1)$ & $5(10.4)$ & $15(31.2)$ & $15(31.2)$ & $\begin{array}{l}2.143 \\
(0.921-\end{array}$ & 0.077 \\
\hline & & & & & & $4.987)$ & \\
\hline $1 \mathrm{~km}$ & $146(75.3)$ & $40(27.4)$ & $18(12.3)$ & $28(19.2)$ & $60(41.1)$ & 1.000 & \\
\hline
\end{tabular}

*Statistically significant factors $(p<0.05)$ for LPF treatment outcome were included in multivariate model.

Table 3: Bivariate analysis of malaria control practices associated with treatment outcomes

Location in main text: page 13, after line 262 


\begin{tabular}{|c|c|c|c|c|c|c|c|}
\hline & $\begin{array}{l}\text { No. of } \\
\text { participants, } \\
\text { N (\%) }\end{array}$ & $\begin{array}{l}\text { ACPR } \\
(n=53)\end{array}$ & $\begin{array}{l}\text { LCF } \\
(n=23)\end{array}$ & $\begin{array}{l}\text { LPF } \\
(n=43)\end{array}$ & $\begin{array}{l}\text { ETF } \\
(n=75)\end{array}$ & $\begin{array}{l}\mathrm{COR} \\
(95 \% \\
\mathrm{Cl})\end{array}$ & $\begin{array}{l}\mathrm{P}- \\
\text { value }\end{array}$ \\
\hline \multicolumn{8}{|c|}{$\begin{array}{l}\text { Practice indoor } \\
\text { residual spraying } \\
\text { at home }\end{array}$} \\
\hline Yes & $82(42.3)$ & $15(18.3)$ & $10(12.2)$ & 13(15.9) & $44(53.7)$ & $\begin{array}{l}0.305 \\
(0.138- \\
0.677)\end{array}$ & $0.004^{*}$ \\
\hline No & 112(57.7) & 38(33.9) & $13(1.6)$ & $30(26.8)$ & $31(27.7)$ & 1.000 & \\
\hline \multicolumn{8}{|c|}{$\begin{array}{l}\text { Source of indoor } \\
\text { residual spraying }\end{array}$} \\
\hline Government & $66(78.6)$ & 13(19.7) & $7(10.6)$ & $8(12.1)$ & $38(57.6)$ & $\begin{array}{l}0.253 \\
(0.062- \\
1.035)\end{array}$ & 0.056 \\
\hline Yourself & $4(22.2)$ & $4(2.2)$ & $3(16.7)$ & $5(27.8)$ & 6(33.3) & & \\
\hline \multicolumn{8}{|l|}{$\begin{array}{l}\text { Last indoor } \\
\text { residual spraying }\end{array}$} \\
\hline$<6$ months & 19(22.9) & $2(10.5)$ & $3(15.8)$ & $3(15.8)$ & 11(57.9) & $\begin{array}{l}0.900 \\
(0.209- \\
3.874)\end{array}$ & 0.887 \\
\hline$\geq 6$ months & 64(77.1) & 14(21.9) & $7(10.9)$ & 10(15.6) & $33(51.6)$ & 1.000 & \\
\hline \multicolumn{8}{|l|}{$\begin{array}{l}\text { Sleep under } \\
\text { mosquito net }\end{array}$} \\
\hline Yes & 162(83.5) & $49(30.2)$ & 19(11.7) & $29(17.9)$ & $65(40.1)$ & $\begin{array}{l}0.319 \\
(0.127- \\
0.801)\end{array}$ & $0.015^{\star}$ \\
\hline No & $32(16.5)$ & $4(12.5)$ & $4(12.5)$ & $14(43.8)$ & $10(31.2)$ & 1.00 & \\
\hline \multicolumn{8}{|l|}{$\begin{array}{l}\text { Mosquito net } \\
\text { treatment }\end{array}$} \\
\hline Yes & $73(45.1)$ & 23(31.5) & $6(8.2)$ & $7(9.6)$ & $37(50.7)$ & $\begin{array}{l}0.241 \\
(0.090- \\
0.643)\end{array}$ & $0.004^{*}$ \\
\hline No & $89(54.9)$ & $26(29.2)$ & $13(14.6)$ & $22(24.7)$ & $28(31.5)$ & 1.000 & \\
\hline \multicolumn{8}{|l|}{$\begin{array}{l}\text { Number of } \\
\text { mosquito nets } \\
\text { owned }\end{array}$} \\
\hline One & $92(56.4)$ & $33(35.9)$ & $14(15.4)$ & $16(17.4)$ & $29(31.5)$ & $\begin{array}{l}1.570 \\
(0.652- \\
3.780)\end{array}$ & 0.314 \\
\hline More than one & $70(43.2)$ & 16(22.9) & $4(5.7)$ & 13(18.6) & $37(52.9)$ & & \\
\hline
\end{tabular}




\begin{tabular}{|c|c|c|c|c|c|c|c|}
\hline \multicolumn{8}{|l|}{$\begin{array}{l}\text { Source of } \\
\text { mosquito net }\end{array}$} \\
\hline $\begin{array}{l}\text { Government } \\
\text { facility }\end{array}$ & $90(56.2)$ & $30(33.3)$ & $7(7.7)$ & $11(12.1)$ & $43(47.3)$ & $\begin{array}{l}0.179 \\
(0.056- \\
0.578)\end{array}$ & $0.004^{*}$ \\
\hline $\begin{array}{l}\text { Pharmacy } \\
\text { shop/open market }\end{array}$ & $43(26.5)$ & $11(25.6)$ & $11(25.6)$ & $7(16.3)$ & $14(32.6)$ & $\begin{array}{l}0.350 \\
(0.093- \\
1.317)\end{array}$ & 0.120 \\
\hline Malaria campaign & $6(3.7)$ & $4(66.7)$ & 0 & $1(16.7)$ & $1(16.7)$ & $\begin{array}{l}0.700 \\
(0.037- \\
13.179)\end{array}$ & 0.812 \\
\hline Hawkers & $22(13.65)$ & $4(18.2)$ & $1(4.5)$ & $10(45.5)$ & $17(31.8)$ & 1.000 & \\
\hline \multicolumn{8}{|l|}{$\begin{array}{l}\text { Have vegetation } \\
\text { near homestead }\end{array}$} \\
\hline Yes & $159(82.0)$ & $43(27.0)$ & $20(12.6)$ & $35(22.2)$ & $61(38.4)$ & $\begin{array}{l}1.004 \\
(0.383- \\
2.630)\end{array}$ & 0.993 \\
\hline No & $35(18.0)$ & $10(28.6)$ & $3(8.6)$ & $8(22.9)$ & $14(40.0)$ & 1.000 & \\
\hline \multicolumn{8}{|l|}{$\begin{array}{l}\text { Have stagnant } \\
\text { water near } \\
\text { homestead }\end{array}$} \\
\hline Yes & $108(55.7)$ & $30(27.8)$ & 15(13.9) & $28(25.9)$ & $35(32.4)$ & $\begin{array}{l}2.133 \\
(0.984- \\
4.626)\end{array}$ & 0.055 \\
\hline No & $86(44.3)$ & $23(26.7)$ & $8(9.3)$ & $15(17.4)$ & $40(46.5)$ & 1.000 & \\
\hline
\end{tabular}

*Statistically significant factors $(p<0.05)$ for LPF treatment outcome were included in multivariate model.

Table 4: Multivariate regression analysis of predisposing factors associated with treatment outcomes

Location in main text: page 13, after line 269 


\begin{tabular}{|llll|}
\hline Predictor variable & Adjusted Odds ratio & $95 \%$ C I & P-value \\
\hline Ability of finishing antimalarial dose & & & \\
\hline Yes & 2.635 & $0.067-10.307$ & 0.604 \\
\hline No & 1.000 & & \\
\hline Reasons for stopping prescribed dose & & & \\
\hline When I feel healed & 6.348 & $0.170-23.735$ & 0.317 \\
\hline When I complete dose & 1.00 & & \\
\hline Practice indoor residual spraying at home & & & $0.001^{*}$ \\
\hline Yes & 0.151 & $0.047-0.479$ & \\
\hline No & 1.000 & & 0.151 \\
\hline Frequency of malaria infection per year & & $0.072-1.500$ & $0.004^{*}$ \\
\hline Once in 3 months & 0.329 & $0.034-0.526$ & \\
\hline Once in a year & 0.133 & & \\
\hline Twice a year & 1.00 & $0.085-0.938$ & $0.039^{*}$ \\
\hline Is mosquito net treated? & & & \\
\hline Yes & 0.283 & 1.000 & \\
\hline No & & & \\
\hline
\end{tabular}

*Statistically significant risk factors for LPF treatment outcome at $p \leq 0.05$.

\section{Figures}




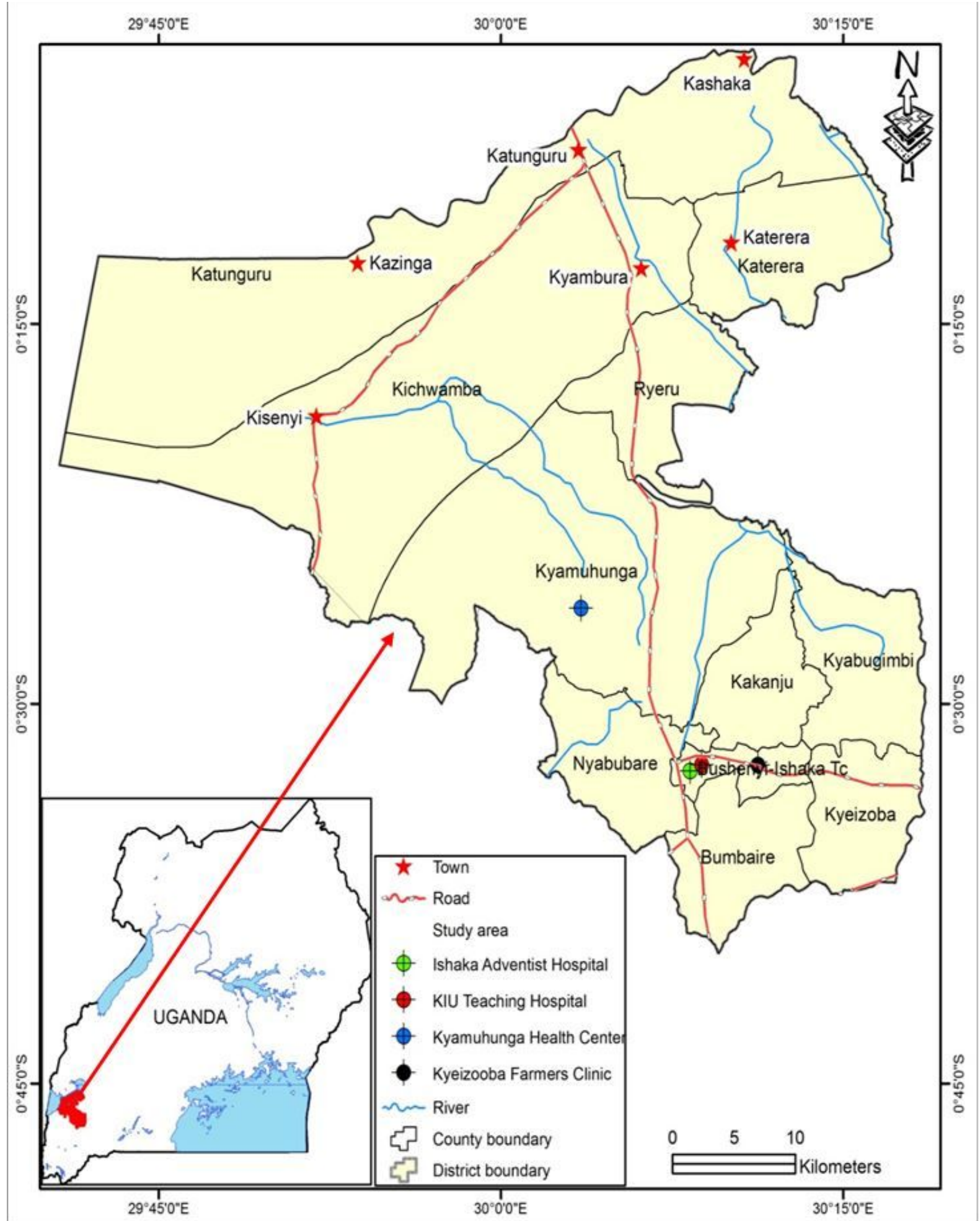

Figure 1

Inset- Map of Uganda showing Bushenyi district (shaded) and the map of Bushenyi district showing the study sites (Uganda Bureau of Statistics). Note: The designations employed and the presentation of the material on this map do not imply the expression of any opinion whatsoever on the part of Research Square concerning the legal status of any country, territory, city or area or of its authorities, or concerning the delimitation of its frontiers or boundaries. This map has been provided by the authors. 